\title{
Erratum to: Morphological and immunological characteristics of nanobacteria from human renal stones of a north Indian population
}

\author{
Madhu Khullar · S. K. Sharma $\cdot$ S. K. Singh • \\ Pratibha Bajwa $\cdot$ Farooq A. Shiekh • \\ Vandana Relan $\cdot$ Meera Sharma
}

Published online: 16 September 2012

(C) Springer-Verlag 2012

Erratum to: Urol Res (2004) 32:190-195

DOI: 10.1007/s00240-004-0400-3

In the original article, one of the co-author's (Farooq A. Shiekh) surname has been published incorrectly. The correct surname should be Shiekh.

The online version of the original article can be found under doi:10.1007/s00240-004-0400-3.

M. Khullar $(\bowtie) \cdot$ P. Bajwa · F. A. Shiekh · V. Relan Department of Experiment Medicine and Biotechnology, Postgraduate Institute of Medical Education and Research, 160012 Chandigarh, India

e-mail: madhu_khullar@hotmail.com

S. K. Sharma · S. K. Singh

Department of Urology, Postgraduate Institute of Medical

Education and Research, 160012 Chandigarh, India

\section{Sharma}

Department of Medical Microbiology,

Postgraduate Institute of Medical Education and Research,

160012 Chandigarh, India 